\title{
Ant proliferative activity of eo extracted from different aromatic plants on different cell lines
}

\begin{abstract}
Essential Oils (EOs) are used in many products to be intended for human utilization Despite their pharmacological applications in the folk and traditional medicine, studies on EO anti-proliferative properties are still limited. The aim of this study was to investigate the anti-proliferative properties of hydrodistilled EO from 16 aromatic plants grown in Yemen. The cytotoxicity of the EOs was determined against seven cell lines namely; HeLa, MCF7, MDA-MB 231, CEMss, WEHI-3B, 3T3 and CHO cell lines using the 3-[4,5-dimethylthiazol-2-yl]-2,5-diphenyltetrazolium (MTT) assay. Lantana camara EO was the most cytotoxic extract against all tested cell lines with an IC50 value of $\leq 0.01 \%$ (v/v), except the non-tumorous cell lines CHO with IC50 value of $0.025 \% \pm 0.005 \% \mathrm{v} / \mathrm{v}$. While Cinnamomum zeylanicum EO showed high cytotoxic activity against HeLa, MDAMB 231, $3 \mathrm{~T} 3$ and CHO cell lines with IC50 value of $\leq 0.010 \%$ (v/v). EO from Ocimum basilicum and Mentha piperita were among the ones with no activity or IC50 value of $>0.010 \%(\mathrm{v} / \mathrm{v})$. The results demonstrated the potential of the EO from aromatic plants from Yemen for possible source of cancer treatment
\end{abstract}

Keywords: cytotoxicity, antioxidants, eos, cell lines, medicinal plants

\author{
Volume 3 Issue 6 - 2017
}

\author{
Adel S Al-Zubairi, ${ }^{1,4}$ Mohamed Al-Mamary, 2,5 \\ Eftekhar Al-Ghasani, ${ }^{3}$ Ahmad Bustamam \\ Abdul, ${ }^{6}$ Syam Mohan ${ }^{7}$ \\ 'Department of Lab Medicine, Albaha University, Saudi Arabia \\ 2Department of Chemistry, Taibah University, Saudi Arabia \\ ${ }^{3}$ Department of Biology, University of Sana'a, Yemen \\ ${ }^{4}$ Department of Biochemistry, University of Sana'a, Yemen \\ ${ }^{5}$ Department of Organic Chemistry, University of Sana'a, Yemen \\ 'UPM-MAKNA Cancer Research Lab, University of Putra \\ Malaysia, Malaysia \\ ${ }^{7}$ Medical Research Center, Jazan University, Saudi Arabia
}

Correspondence: Adel S Al-Zubairi, Department of Lab Medicine, Faculty of Applied Medical Sciences, Albaha University, KSA, Saudi Arabia, Tel +9665409944I5, 967I37468I, Email adelalzubairi@hotmail.com

Received: October 19, 2017 | Published: October 26, 2017

\section{Introduction}

Essential oils (EOs) recently have got substantial importance in phytomedicine ${ }^{1,2}$ due to their increase application in various industries of perfumery, cosmetics, pharmaceutical and foods. They have shown great biological activities, such as antimicrobial and antioxidant activities. ${ }^{3-5}$ EOs are concentrated oily liquids extracted from different plant parts, such as flowers, buds, seeds, twigs, bark, herbs, wood, fruits or roots. They are very complex mixtures of complex compounds derived from terpenes and their oxygenated compounds, such as monoterpenes and sesquiterpenes, with the general formula (C5H8)n. These compounds could include alcohols, aldehydes, esters, ethers, ketones, phenols, and oxides. They have shown to possess antibacterial, antifungal, antiviral, and antioxidant activities. ${ }^{6,7}$ In addition, some EOs have been used in cancer treatment, ${ }^{2}$ aromatherapy, food preservation ${ }^{8}$ and fragrance industries.

EOs represent good source for a vast array of bioactive biological compounds with good antioxidants, anticancer and antibacterial activities as well as food additives and preservatives. Cancer chemotherapy has life-threatening side effects manifested by the complication of the chemotherapy in addition to the anticancer drug resistance necessitate the search for natural anticancer agents that proven to have fewer side effects to cancer patients. As a result, there are great efforts to replace synthetic anticancer compounds by natural secondary metabolites, such as EOs. For identification and development of novel anticancer agents, natural products remain the potential source for anticancer drug discovery, since the majority of the anticancer drugs used are of natural origin., ${ }^{9,10}$ Compounds isolated from natural products played an important role in anticancer therapy, since about half of the anticancer drugs used during the last decades are of natural resources. ${ }^{11,12}$ Their contents of phytochemicals that can suppress cancer initiation and development, inhibit cellular proliferation, reduce inflammatory process and malignancy transformation, EOs considered a promising resource as anticancer. ${ }^{13,14}$ At present time various industries, are looking into sources of alternative, more natural and environmentally friendly. In other words, pharmaceutical firms are mainly interested in the discovery of active chemical structures from which can develop and prepare synthetic analogues. These are more controllable from point of reproducibility, patentability, safety, and are more economically viable. Therefore, the present work, aimed to screen EO from sixteen herbal plants grown in Yemen for their antiproliferative activity against seven cell lines.

\section{Materials and methods}

\section{Plant materials}

Plant materials were collected during summer 2008, from three different regions in Yemen. They were identified by Dr Abdulwali Ahmed Al-Khulaidi, the botanists at the Department of Biology, Faculty of Sciences, Taiz University. The plants, which screened for their antiproliferative activities are shown Table 1.

\section{Extraction of EOs}

Two hundred grams $(200 \mathrm{~g})$ of plant samples were subjected to hydrodistillation for approximately three hours using a Clevenger type apparatus. The oil layer was collected, however, in some cases the distillate aqueous layers were washed with ether to extract any dissolved oils in water. Then, the ether was separated by separatory funnel and evaporated on water bath at $40^{\circ} \mathrm{C}$ and the residue $\mathrm{EO}$ was added to the first collected portion. The EO was dried over anhydrous sodium sulfate and the yield was calculated. 
Table I Aromatic plants, site of their collection, and parts used for EOs hydrodistillation

\begin{tabular}{lll}
\hline Botanical name & Site of collection part used & Botanical name \\
\hline Artemisia abrotanum & Thamar & Aerial parts \\
Chenopdium ambrosioides & Sana'a & Fresh whole plant \\
Cinnamomum zylanicum & Imported (India) & Bark \\
Clove Eugenia caryophyllata & Imported (India) & Fruits \\
Conyza incana (Vah) willd & Taiz-Hojariah & Seeds \\
Coriandrum sativum & Sana'a & Seeds \\
Eucalyptus camaldulensis & Sana'a & Dried leaves \\
Lantana camara & Sana'a & Fresh leaves \\
Mentha piperita & Amran & Fresh leaves \\
Ocimum basilicum & Sana'a & Fresh leaves \\
Origanum majorana hortensis & Sana'a & Fresh aerial part \\
Rosmarinus officinalis & Sana'a & Fresh leaves \\
Pulicaria jaubertii & Sana'a & Fresh aerial parts \\
Schinus molle & Sana'a & Fruits \\
Tagetes minuta & Sana'a & Fresh aerial parts \\
Thymus laevigatus & Sana'a-Alhimah & Dried aerial parts \\
\hline
\end{tabular}

\section{Cell cultures and maintenance}

Human cervical cancer cells (HeLa), human breast cancer cell lines (MCF-7), human mammary cancer cell lines-estrogen negative (MDA-MB-231), human colon carcinoma cell lines (HT-29), mouse fibroblast cell lines (3T3) and murine monomyelocytic leukemia cell lines (WEHI-3) were obtained from ATTC. While Chinese hamster ovary cell line $(\mathrm{CHO})$ from ECACC and T4-lymphoplastoid cell lines (CEMss) from NIH (AIDS Research and Reference Reagent Program, Division of AIDS, NIAID, NIH: USA). Cell lines were grown in RPMI 1640 supplemented with $10 \%$ fetal calf serum, $1 \%$ penicillin-streptomycin and $1 \%$ amphotericin B. Flasks containing cell lines were incubated in a humidified incubator with $5 \% \mathrm{CO}_{2}$, at $37^{\circ} \mathrm{C}$. Cultures were frequently examined under inverted microscope (Micros, Austria). Once cells reached 80\% confluency, media was removed and the cells were washed 3 times with $7 \mathrm{~mL}$ of PBS (Phosphate Buffer Saline). Two milliliters of trypsin was added to the adherent cells and were incubated for 5 minutes. The flask was tapped gently to detach cells from the wall of the flask to appear as single cells. Ten milliliters of RPMI 1640 with $10 \%$ FCS were added to the flask and the content of the flask was resuspended to allow cells to disperse. About $6 \mathrm{~mL}$ of cell suspension was transferred into a $75 \mathrm{~cm}^{3}$ flask. Ten milliliters of RPMI 1640 with $10 \%$ FCS were then added and incubated in $\mathrm{CO}_{2}$ incubator at $37^{\circ} \mathrm{C}$. The cells were frequently examined under an inverted microscope for confluency and viability.

\section{Cytotoxicity assay (MTT)}

EOs were solubilized with DMSO and diluted in RPMI 1640 media to give final concentrations of $10 \mu \mathrm{l} / \mathrm{mL}$. Substock solution of $100 \mu \mathrm{M}$ cisplatin was prepared from the stock solution $1 \mathrm{mg} / \mathrm{mL}$ as a control for the test system. Cells were washed 3 times with $7 \mathrm{~mL}$ of PBS and $2.5 \mathrm{~mL}$ of trypsin were added to the adherent cells and were incubated for 5 minutes in the $\mathrm{CO}_{2}$ incubator. Once the cells were detached from the flask, $10 \mathrm{~mL}$ of RPMI with $5 \%$ FCS was added. Cells density was determined using a hemocytometer. One hundred microliters of cell suspension were plated in each well of 96 well plates at concentration of $1 \times 10^{5}$ cells $/ \mathrm{mL}$. After 24 hours incubation, content of each well was decanted and cells were treated with different concentrations of EOs (in a concentration range of 0.015 to $2.0 \mu \mathrm{l} / \mathrm{mL}, 0.1 \%$ DMSO and cisplatin (as negative and positive controls, respectively). The cells were incubated in $\mathrm{CO}_{2}$ incubator at $37^{\circ} \mathrm{C}$ for 3 days (72hours). The MTT (3-(4,5-dimethyl-thiazol-2-yl)-2,5-diphenyl tetrazolium bromide) assay used has been described by Mossman (1983), ${ }^{15}$ powder was purchased from Amresco and the DMSO (Dimethylsulphoxide) was purchased from Sigma Aldrich, Germany. Twenty microliters of $5 \mathrm{mg} / \mathrm{mL}$ MTT (Micro culture Tetrazolium) solution was added into each well. Plates were covered with aluminum foil and incubated at $37^{\circ} \mathrm{C}\left(5 \% \mathrm{CO}_{2}\right)$ for 4 hours in dark in order to allow the active live cells to convert water soluble yellow MTT solution into water insoluble purple formazan. After 4 hours of incubation, the media containing MTT solution was aspirated. The remaining purple formazan was dissolved by adding $100 \mu 1$ DMSO into each well. MTT assay reading was performed using ELISA plate reader at 450nm (TECAN, SunriseTM, Männedorf, Switzerland). The IC50 value (Concentration at which $50 \%$ of the cells are viable and another $50 \%$ cells killed) was determined from the dose-response curve (\%cell viability versus concentration of EO or cisplatin). 


\section{Results and discussion}

Seven cell lines have been exposed to increasing concentrations of EOs, namely HeLa, MCF-7, MDA-MB-231, 3T3 CEMss, WEHI$3 \mathrm{~B}$ and $\mathrm{CHO}$ cell lines. Cell survival was determined by the MTT assay. In vitro cytotoxic activity of the EOs is shown in Table 2. The EOs revealed different cytotoxic activities towards the seven cell lines under investigation. Results present the IC50 values of the EOs (the EO concentration needed to reduce proliferation by $50 \%$ after $72 \mathrm{~h}$ of incubation compared to control wells). IC50 values were determined by plotting dose response curve for the EO in the range of ( 0.0015 to $0.100 \% \mathrm{v} / \mathrm{v})$. The IC50 value of the reference drug cisplatin ranged from 3.1 to $16.1 \mu \mathrm{g} / \mathrm{mL}$ against all tested cell lines. Lantan camara EO exhibited the most effective cytotoxic activity towards most of the cell lines tested with an IC50 $\leq 0.01 \% \mathrm{v} / \mathrm{v})$, except $\mathrm{CHO}$ cell lines in which the IC50 value was found to be $(0.025 \pm 0.005 \% \mathrm{v} / \mathrm{v})$. In contrast, Lantana camara EO exhibited less pronounced cytotoxicity against $\mathrm{CHO}$ cell line, a non-tumorous cell line, which makes it promising as a good anticancer candidate for further investigations. The cytotoxicity of oleanonic acid extracted from Lantana camara has been described previously and found to exhibit promising anticancer activity against A375 (malignant skin melanoma) cell lines. ${ }^{16}$ Meanwhile the leaf extract was found to exhibit a strong antioxidant effect using the DPPH and the reducing power assays. ${ }^{17,18}$ The other active EO with cytotoxic activity was the essential of Cinnamomum zylanicum in which the IC50 value towards HeLa,
MDA-MB-231, 3T3 and CHO was shown to be $(0.006 \pm 0.0003$, $0.008 \pm 0.0002,0.006 \pm 0.0009$ and $0.006 \pm 0.0007 \% \mathrm{v} / \mathrm{v}$, respectively). In addition, EOs of Eucalyptus camaldulensis and Thymus laevingatus were found to have marked cytotoxicity against some cell lines. They were found to be active against the leukemic cell lines, CEMss (IC50 $=0.0063 \pm 0.0012$ and $0.007 \pm 0.0005 \% \mathrm{v} / \mathrm{v}$ respectively) and WEHI-3B (IC50 $=0.0063 \pm 0.0006$ and $0.0065 \pm 0.0007 \% \mathrm{v} / \mathrm{v}$ respectively). In addition EO from Schinus molle was found to be active against WEHI-3B (IC50 $=0.008 \pm 0.0002 \% \mathrm{v} / \mathrm{v})$, Tagetes minuta against MDA-MB-231 (IC50 $=0.003 \pm 0.0006 \% \mathrm{v} / \mathrm{v})$ and Coriandrum sativum against CEMss (IC50 $=0.0065 \pm 0.0007 \% \mathrm{v} / \mathrm{v}$ ). Meanwhile, all the EOs were shown to exhibit less or no cytotoxic activity towards the normal epithelial cell lines $\mathrm{CHO}$ except the Cinnamomum zylanicum EO (Table-2). Cytotoxicity of the EOs could be attributed to their constituents of complex mixtures of monoterpenes and sesqueterpenes as reported in the literature. ${ }^{19}$ Antitumor activity of EOs has been reported by various authors, such as the EO of thyme, which contains carvacrol, has a marked in vitro cytotoxic activity against tumor cells.$^{20}$ In this study, the EOs displayed the strongest antiproliferative activity was found to show moderate antioxidant activity (unpublished work) suggesting that antioxidant effects have moderate effects on the antiproliferative activity. This observation has been supported statistically by Baharum and his coworkers, ${ }^{21}$ who reported that the anti-cancer activities of Theobroma cacao plant extracts showed negative moderate correlation with their antioxidant activity.

Table 2 The cytotoxicity effects of different levels of EOs

\begin{tabular}{|c|c|c|c|c|c|c|c|}
\hline \multirow{2}{*}{ Essential oil } & \multicolumn{7}{|c|}{ Cell lines [IC50 (Mean士STD) (\%v/v) } \\
\hline & HeLa & MCF-7 & MDA-MB 23I & CEMss & WEHI-3B & $3 T 3$ & $\mathrm{CHO}$ \\
\hline Artimisia abrotanum & $0.042 \pm 0.0045$ & $0.062 \pm 0.008$ & $0.10 \pm 0.005$ & $0.025 \pm 0.006$ & ND & ND & $0.0125 \pm 0.004$ \\
\hline Chenopdium ambrosioides & $0.055 \pm 0.0070$ & $0.02 I \pm 0.003$ & $0.020 \pm 0.007$ & $0.025 \pm 0.003$ & $0.0125 \pm 0.003$ & $0.023 \pm 0.007$ & $0.035 \pm 0.015$ \\
\hline Cinnamomum zeylanicum & $0.007 \pm 0.0003$ & $0.012 \pm 0.005$ & $0.008 \pm 0.002$ & $0.028 \pm 0.005$ & ND & $0.006 \pm 0.0009$ & $0.006 \pm 0.0007$ \\
\hline Conyza incana (vah ) willd & $0.036 \pm 0.008$ & $0.027 \pm 0.005$ & $0.012 \pm 0.003$ & $0.0125 \pm 0.004$ & $0.0127 \pm 0.008$ & $0.0150 \pm 0.005$ & $0.018 \pm 0.007$ \\
\hline Coriandrum sativum & no activity & no activity & no activity & $0.0065 \pm 0.0007$ & $0.025 \pm 0.009$ & $0.050 \pm 0.008$ & $0.090 \pm 0.008$ \\
\hline Clove Eugenia caryophyllata & $0.024 \pm 0.004$ & $0.025 \pm 0.005$ & $0.032 \pm 0.006$ & $0.015 \pm 0.0016$ & ND & $0.027 \pm 0.005$ & $0.060 \pm 0.008$ \\
\hline Eucalyptus camaldulensis & $0.13 \pm 0.031$ & $0.107 \pm 0.021$ & $0.055 \pm 0.003$ & $0.0063 \pm 0.0012$ & $0.0063 \pm 0.0006$ & $0.011 \pm 0.04$ & $0.023 \pm 0.004$ \\
\hline Lantana camara & $0.008 \pm 0.0035$ & $0.0063 \pm 0.0008$ & $0.0063 \pm 0.0004$ & $0.0031 \pm 0.0002$ & $0.0068 \pm 0.0006$ & $0.0100 \pm 0.003$ & $0.025 \pm 0.005$ \\
\hline Mentha piperita & no activity & no activity & $0.210 \pm 0.05$ & $0.0125 \pm 0.003$ & $0.020 \pm 0.006$ & $0.120 \pm 0.020$ & no activity \\
\hline Ocimum basilicum & no activity & no activity & $0.20 \pm 0.04$ & $0.025 \pm 0.004$ & $0.0185 \pm 0.0004$ & $0.035 \pm 0.008$ & $0.060 \pm 0.005$ \\
\hline Origanum majorana & $0.15 \pm 0.030$ & $0.110 \pm 0.020$ & $0.11 \pm 0.004$ & $0.036 \pm 0.005$ & $0.035 \pm 0.005$ & $0.025 \pm 0.006$ & $0.040 \pm 0.006$ \\
\hline Pulicaria jaubertii & $0.080 \pm 0.020$ & $0.060 \pm 0.007$ & $0.060 \pm 0.0055$ & $0.070 \pm 0.0035$ & $0.0125 \pm 0.004$ & $0.038 \pm 0.008$ & $0.080 \pm 0.006$ \\
\hline Rosmarinus officinalis & $0.130 \pm 0.027$ & $0.112 \pm 0.018$ & $0.110 \pm 0.02$ & $0.025 \pm 0.007$ & $0.028 \pm 0.006$ & $0.060 \pm 0.009$ & $0.080 \pm 0.009$ \\
\hline Schinus molle & $0.065 \pm 0.016$ & $0.045 \pm 0.005$ & $0.040 \pm 0.006$ & $0.025 \pm 0.004$ & $0.0080 \pm 0.0002$ & $0.013 \pm 0.007$ & $0.022 \pm 0.003$ \\
\hline Tagetes minuta & $0.054 \pm 0.007$ & $0.020 \pm 0.001$ & $0.003 \pm 0.0006$ & $0.030 \pm 0.0035$ & ND & ND & $0.0125 \pm 0.003$ \\
\hline Thymus laevigatus & $0.032 \pm 0.006$ & $0.027 \pm 0.006$ & $0.018 \pm 0.003$ & $0.007 \pm 0.0005$ & $0.0065 \pm 0.0007$ & $0.0115 \pm 0.003$ & $0.023 \pm 0.006$ \\
\hline Cisplatin $(\mu \mathrm{g} / \mathrm{mL})$ & $4.2 \pm 0.05$ & $15.0 \pm 0.13$ & $16.1 \pm 0.20$ & $7.6 \pm 0.08$ & $3.10 \pm 0.28$ & $4.20 \pm 0.06$ & $4.40 \pm 0.08$ \\
\hline
\end{tabular}

Stock solution of the EO was prepared by dissolving the EO in DMSO (final conc. No more than I\%) and diluted by culture media to give a concentration of $\mathrm{I} \mu \mathrm{EO} / \mathrm{mL}$ media.

ND: NOT Determined 


\section{Conclusion}

Lantana camara EO was the most cytotoxic extract against all tested cell lines, except the non-tumorous cell lines CHO. While Cinnamomum zeylanicum EO showed high cytotoxic activity against HeLa, MDA-MB 231, 3 T3 and CHO cell lines. EOs from Ocimum basilicum and Mentha piperita were among the ones with no activity or low IC50 value. The EOs from different plants were shown to exhibit less or no cytotoxic activity towards the normal epithelial cell lines $\mathrm{CHO}$ except the Cinnamomum zylanicum EO. Chemical constituent analysis of those effective oils will be beneficial for further development of new chemotherapeutic agents. These results demonstrated the potential beneficial use of the EOs extracted from aromatic plants from Yemen as possible source of cancer treatmen

\section{Acknowledgements}

The authors would like to extent their utmost gratitude and appreciation to the MAKNA-UPM Cancer research Lab., Institute of Biosciences, University of Putra Malaysia for their cooperation in performing the cytotoxicity assay.

\section{Conflict of interest}

The author declares no conflict of interest.

\section{References}

1. Buckle J. Use of aromatherapy as a complementary treatment for chronic pain. Altern Ther Health Med. 1999;5(5):42-51.

2. Sylvestre M, Pichette A, Longtin A, et al. EO analysis and anticancer activity of leaf EO of Croton flavens L. from Guadeloupe. $J$ Ethnopharmacol. 2006;103(1):99-102.

3. Aligiannis N, Kalpoutzakis E, Chinou IB, et al. Composition and antimicrobial activity of the EOs of five taxa of Sideritis from Greece. $J$ Agric Food Chem. 2001;49(2):811-815.

4. Salehi P, Sonboli A, Eftekhar F, et al. EO composition, antibacterial and antioxidant activity of the oil and various extracts of Ziziphoraclinopodioides subsp. rigida (BOISS.) RECH.f. from Iran. Biol Pharma Bull. 2005;28(10):1892-1896.

5. Magwa ML, Gundidza M, Gweru N, et al. Chemical composition and biological activities of EO from the leaves of Sesuviumportulacastrum. $J$ Ethnopharmacol. 2006;103(1):85-89.

6. Burt S. EOs: their antibacterial properties and potential applications in foods- a review. Int J Food Microbiol. 2004;94(3):223-253.

7. Kordali S, Kotan R, Mavi A, et al. Determination of the chemical composition and antioxidant activity of the EO of Artemisia dracunculus and of the antifungal and antibacterial activities of Turkish Artemisia absinthium, A. dracunculus, Artemisia santonicum, and Artemisia spicigera EOs. J Agric Food Chem. 2005;53(24):9452-9458.
8. Faid M, Bakhy K, Anchad M, et al. Almond paste:physicochemical and microbiological characterization and preservation with sorbic acid and cinnamon. J Food Protect. 1995;58(5):547-550.

9. Newman DJ, Cragg GM. Natural products as sources of new drugs over the last 25 years. J Nat Prod. 2007;70(3):461-477.

10. Efferth T, Fu YJ, Zu YG, et al. Molecular target-guided tumor therapy with natural products derived from traditional Chinese medicine. Curr Med Chem. 2007;14(19):2024-2032.

11. Lee KH. Anticancer drug design based on plant-derived natural products. J Biomed Sci. 1999;6(4):236-250.

12. Koo HN, Hong SH, Song BK, et al. Taraxacum officinale induces cytotoxicity through TNF-alpha and IL-1alpha secretion in Hep G2 cells. Life Sci. 2004;74(9):1149-1157.

13. Bhalla Y, Gupta VK, Jaitak V. Anticancer activity of EOs:a review. J Sci Food Agric. 2013;93(15):3643-3653.

14. Gautam N, Mantha AK., Mittal S. EOs and their constituents as anticancer agents: a mechanistic view. Biomed Res Int. 2014;2014:154106.

15. Mossman T. Rapid colorimetric assay for cellular growth and survival:application to proliferation and cytotoxicity assays. J Immunol Methods. 1983;65(1-2):55-63.

16. Ghosh S, Das Sarma M, Patra A, et al. Anti-inflammatory and anticancer compounds isolated from Ventilago madraspatana Gaertn. Rubia cordifolia L inn. and Lantana camara Linn. J Pharm Pharmacol. 2010;62(9):1158-1166.

17. Bhakta D, Ganjewala D. Effect of leaf positions on total phenolics, flavonoids and proantho-cyanidins content and antioxidant activities in Lantana camara (L). J Sci Res. 2009;1(2):363-369.

18. Mayee R, Thosar A. Evaluation of Lantana camara Linn. (Verbenaceae) for antiurolithiatic and antioxidant activities in rats. Int $J$ Pharmaceut Clin Res. 2011;3(1):10-14.

19. Wiseman DA, Werner SR, Crowell PL. Cell cycle arrest by the isoprenoids perillyl alcohol, geraniol, and farnesol is mediated by $\mathrm{p} 21$ (Cip1) and p27 (Kip1) in human pancreatic adenocarcinoma cells. $J$ Pharmacol Exp Ther. 2007;320(3):1163-1170.

20. Mbarek AL, Ait Mouse H, Jaafari A, et al. Cytotoxic effect of EO of thyme (Thymus broussonettii) on the IGR-OV1 tumor cells resistant to chemotherapy. Braz J Med Biol Res. 2007;40(11):1537-1544.

21. Baharum Z, Akim AM, Taufiq-Yap YH, et al. In Vitro Antioxidant and Antiproliferative Activities of Methanolic Plant Part Extracts of Theobroma cacao. Molecules. 2014;19(11):18317-18331. 